\title{
Via do espanto: teatralidade e antiteatralidade na cena contemporânea
}

\author{
ARTHUR E. A. BELLONI
}

\section{Resumo}

$\mathrm{O}$ artigo se vale de algumas ideias e conceituações teóricas defendidas por filósofos, críticos e pesquisadores da arte e do teatro contemporâneos, como meio de apontar formas de teatralidade e antiteatralidade mobilizadas por uma vertente da cena teatral contemporânea que rompe com a lógica representacional.Para tanto, toma como referência aspectos do universo cênico da Societas Raffaello Sanzio, um dos mais representativos grupos de teatro experimental italiano da atualidade.

Palavras-chave:

Teatralidade, antiteatralidade, teatro performativo 


\title{
Path of fright: theatricality and anti-theatricality in contemporary scene
}

\author{
ARTHUR E. A. BELLONI
}

\begin{abstract}
The article makes use of some ideas and concepts espoused by philosophers, critics and researchers of contemporary art and theater, as a means to point out forms of theatricality and antitheatricality mobilized by a contemporary theatrical trend which breaks up with the representational logic. To this end, it takes as reference some aspects related to the scenic universe of Societas Raffaello Sanzio, currently one of the most representative Italian experimental theater groups.
\end{abstract}

Keywords: Theatricality, anti-theatricality, performative theater 


\begin{abstract}
Ao chamar a atenção para o modo como a tecnologia das mídias - associada ao mecânico, à reprodução e à reprodutibilidade - é teatralizada na cena multimídia contemporânea, Hans-Thies Lehmann (2007) afirma que, no topos high tech dessa modalidade teatral, ocorre uma intensificação e uma desconstrução do teatro nos mais variados níveis: "o teatro 'vivo' é posto em suspensão e passa a ser uma ilusão, um efeito de uma máquina de efeitos. Por outro lado, experimenta-se na atmosfera intensa e vital do trabalho uma tendência inversa: a tecnologia das mídias é teatralizada" (LEHMANN, 2007, p. 384). Para Lehmann, o mecânico, a reprodução e a reprodutibilidade, antes de negar, reafirmam a teatralidade, à medida que servem à atualidade do teatro, e consequentemente, à vida. Nesse sentido, ele questiona se os recursos de multimídia, estando relacionados às técnicas de "ilusionismo", representariam uma ruptura na história do teatro - enquanto "medium" de uma determinada tecnologia da "representação" -, ou se "a incerteza sobre o status de realidade do que é representado, ou seja, mostrado como ilusão, significam apenas uma nova modalidade do maquinário da ilusão que o teatro já conhecia" (Ibidem, p. 374).

Deve-se ressaltar, no entanto, que o "ilusionismo" próprio ao chamado teatro performativo contemporâneo não envolve necessariamente a ideia de ficção. Sobre esse aspecto, cabe lembrar, o que sustenta o próprio Lehmann(2007) quando observa que a chamada "ilusão" pode se manifestar através das seguintes vias: via do Espanto, frente aos efeitos de realidade e aspectos de magia; via da Identificação com a intensidade sensorial dos atores e da cenas, das formas de movimentação (dança) e das sugestões verbais (aspectos de Eros, claro e escuro); via da
\end{abstract}


Projeção de conteúdos ligados ao contexto objetual, associada aos modelos teatrais de representação, aos mentais de "preencher e esvaziar" e à empatia com os personagens, encerrando, nestes termos, uma experiência de mundo própria e estável' ${ }^{1}$.

Como faz destacar o próprio Lehmann, somente o último aspecto diz respeito à ficcionalidade, no sentido estrito do termo, o que explica o fato de que, a despeito do recuo, e até mesmo do desaparecimento da ficção, não se elimina a experiência da "passagem", da "transportação", do "rapto" para o reino da aparência, o qual, por sua vez, costuma ser, de forma apressada, confundido com a ilusão. Tanto a camada relacionada à magia, quanto aquela relacionada ao Eros permanecem, nesse sentido, passíveis de manifestação, independentemente de quaisquer planos de ficção. Em última instância, seria possível dizer, essa análise de Lehmann nos sugere um princípio de resposta a uma questão colocada recentemente por Féral (2008), a saber, o teatro se distanciou da representação, mas ele terá se distanciado, de fato, da teatralidade?

\section{Cantar com o sinus}

Os espetáculos da Societas Raffaello Sanzio conferem um terreno propício à manifestação e, conseqüentemente, à percepção daquilo que poderíamos chamar aqui de uma teatralidade anti-representacional. Formada em Cesena, região de Emmilia Romana, Itália, no ano de 1981, a companhia tornou-se um dos mais representativos grupos de teatro experimental italiano, notabilizando-se, dentre outras coisas, pelo maneira incomum como costuma agenciar um trabalho objetivo, baseado em um objeto pré-existente, e para o qual a invenção do artista não é essencial. No contexto de suas produções, a cena, em vez de ser revelada pela ação do artista, acaba antes por revelar a si própria, como se configurasse um processo fotográfico. Não por acaso o fato de que, ao reunir corpos humanos e não-humanos no palco, Romeo Castellucci, juntamente com sua irmã Claudia Castellucci e os irmãos Chiara e Paolo Guidi - integrantes do núcleo estável da companhia -, costumam adotar, de forma recorrente, critérios de escolha objetivos que se pautam única e exclusivamente por aspectos da ordem da fisicalidade.

Esse tipo de seleção "objetivada" dos elementos da cena, destinando ao artista - por um certo viés - um topos secundário em meio ao processo de criação como um todo, acaba por tornar, francamente, desnecessária a presença de atores profissionais na cena, ainda que não lhes seja, de fato, vetada a par- 
ticipação nas produções da companhia. "Trabalho com atores profissionais, bailarinos, com gente que nunca pôs os pés no palco. Mas não faz diferença. Não é um problema de treinamento. Nunca faço treinamento" ${ }^{2}$. Nesse caso, se, de fato, o recurso à técnica, inevitavelmente, acaba por ocorrer, ele se dá por demandas pontuais, relacionadas a um projeto ou montagem na sua singularidade - como, por exemplo, acontece no Quad, em que Beckett exige dos caminhantes "uma certa experiência da dança"3. Contudo, isso jamais resvala na necessidade de adesão a um tipo de treinamento sistematizado qualquer; e, muito menos, implica a submissão aos preceitos - por vezes, na forma de "fetiche" -, de algum desses "Grandes Mestres" que, segundo Castellucci, começam a desaparecer, após terem "'vampirizado' bastante as gerações joven ${ }^{4}$ ".

A técnica eu a desprezo. Porque é miserável e sem coragem de se declarar. Finge ser sutil para vender-se melhor (...) Temos que superá-la não com a economia que se vai ao teatro. Eu aponto para uma técnica que se supere (...) que repouse na própria operação que desapareceu, agnóstica e sem cortina (...) a super técnica do animal; que repousa dentro de nós. Sem medo de errar. Mas com o temor do pânico de existir. No palco (CASTELLUCCI, 2009, p.141).

Em última instância, pode-se inferir, então, o que está em jogo nessa abordagem cênica mobilizada por Castellucci e seus parceiros, indo para muito além de uma simples incorporação de não-profissionais à cena, parece ser uma radical operação subtrativa cujo intuito consiste na supressão não apenas dos atores, mas de todos os "especialistas" da cena teatral - das artes cênicas, como um todo -, a saber, diretores, dramaturgos, atores, cenógrafos, dançarinos, coreógrafos, etc $^{5}$. Daí a necessidade de um corte profundo na raiz mesma da ideia de representação e seu esquema de "representantes", seus territórios específicos ${ }^{6}$. O que, como já dito, não implica o banimento dos profissionais de cada uma das áreas, mas, antes, elimina a ideia de qualquer tipo de função ou qualidade especificante (subvertendo, além disso, os modelos de criação pautados em estruturações hierárquicas de produção). Afinal, "será tão triste e perigoso não mais suportar os olhos para ver, os pulmões para respirar, a boca para engolir, a língua para falar, o cérebro para pensar, o ânus e a laringe (...)? Por que não caminhar com a cabeça, cantar com o sinus, ver com a pele, respirar com o ventre" (DELEUZE, 1999, p.11)7. 


\section{Cena libidinal}

Resistindo, bravamente e sem qualquer concessão, a qualquer tipo de esquema representacional de ordem fabular, o "teatro de superfície" da $S R S$ alia-se àquela corrente da cena teatral contemporânea na qual, como afirma Fernandes (2009), "o que passa a determinar o trabalho de construção da cena é o princípio da literalidade, responsável por colocar em jogo, ou em confronto, a materialidade dos elementos que constituem a realidade específica do teatro" (FERNANDES, 2009, p.15). Para a Fernandes, a desativação da função simbólica de um objeto por meio da exposição literal do mesmo, nos termos do que ocorre, por exemplo, em teatros da literalidade como os de Tadeusz Kantor, Ian lauwers, Gilles Maheu, Heiner Goebbels e do próprio Castellucci, acaba por gerar situações de linguagem carregadas pela manifestação extremada da matéria teatral, em que o sensível se torna significante.

Quanto ao tipo de "ação" desempenhada pelo grupo de operadores inserido no âmbito das produções da Raffaello Sanzio, talvez seja possível dizer aqui o mesmo que Josette Féral (1997) sustenta em relação ao trabalho do performer, atentando para o fato de que, no contexto performático, diversamente do que ocorre no teatro propriamente dito, a relação do artista com a sua própria performance não se estabelece mais a partir de uma negociação do tipo ator/personagem, chegando-se ao ponto em que se nega, inclusive, a perspectiva do performer vir a assumir o papel de si mesmo, nos termos do que ocorria, por exemplo, em algumas produções do Living Theater. Indo numa outra direção, o performer agora passa a ser o ponto de passagem de fluxos de energia - vocal, libidinal, gestual - que o atravessam sem jamais estabilizarem um significado e/ou uma representação específicos. Em meio a um espaço pleno de deslocamentos e lugares de passagem que mobiliza, a performance nunca quer dizer algo (como o teatro), mas antes provoca relações sinestésicas entre sujeitos, escapando a qualquer formalismo - imobilismo - e optando pelos movimentos descontínuos como meio de despertar o corpo - do espectador e do performer - do estado de torpor que o assombra. Como nos lembra Féral, não há nada a dizer sobre a performance. Resta-nos saber, no entanto, como, em meio a esse topos performático, se estabelece a teatralidade, ou mesmo a sua percepção, propriamente dita. 


\section{O velho e bom teatro?}

Num ensaio sobre a Societas Raffaello Sanzio, Ridout (2006) chama a atenção para o fato de que a companhia italiana sempre foi aclamada pela intensa "realidade" das cenas que costuma produzir, de modo que, os seus trabalhos, comumente, acabam sendo vinculados a uma tradicional corrente da vanguarda européia que, no campo do teatro, tem Artaud como figura emblemática. Um traço marcante da ação das vanguardas, ele nos lembra, está relacionado à insistente ideia de suprimir a distinção entre arte e vida, de modo a garantir que a primeira, ao estabelecer uma relação de continuidade com a segunda, resgate sua capacidade de intervenção ativa e, ao mesmo tempo, elimine todo tipo de relação imitativa para com a vida. Libertando-se de sua relação de dependência escrava com o mundo, a pintura, por exemplo, rompe com a ação figurativa (pintar coisas) e passa, então, a "somente pintar", pura e simplesmente; tipo de ação que, conforme Ridout, no âmbito do teatro, se torna dificultosa, à medida que, a mera exposição de uma pessoa no ambiente cênico já parece nos fazer pressupor que ela esteja ali representando uma outra pessoa. Isso porque o teatro encontra-se intensamente contaminado pelo seu histórico envolvimento com a representação.

De modo que, na concepção de Ridout (2006), essa tendência que existe de ressaltar os aspectos de intensidade do "real" no trabalho da companhia, mais do que qualquer outra coisa, evidencia o êxito do fingimento e da simulação próprios ao teatro. Assim sendo, longe de fazer um teatro afinado com a poética eventual de Artaud, em sua acusação da transcendência da representação teatral expressa por meio da submissão ao significado e ao estereótipo mimético, ou de se alinhar a performers como Kaprow ou Marina Abramovic, para quem, aliás, o teatro é considerado um inimigo, para Ridout, Castellucci e seus parceiros estão, de fato, fazendo o bom e velho teatro, no qual a representação é uma preocupação absolutamente central.

Para sustentar sua teoria, Ridout relata alguns aspectos relacionados ao forte impacto que sofreu quando, pela primeira vez, assistiu a um espetáculo da Societas Raffaelo Sanzio - algo, segundo o próprio, diferente de tudo que, até então, tinha visto no teatro. De acordo com o seu ponto de vista, a explicação mais óbvia para justificar o impacto visceral produzido pela cena, tende a ressaltar os aspectos relacionados aos 
efeitos do "real" promovidos em cena, a partir da experiência de ver, por exemplo, as cordas vocais de uma pessoa, um cavalo vivo e um sujeito, autenticamente, laringotomizado.

Porém, segundo argumenta Ridout, uma imagem das cordas vocais era apresentada, e não as cordas propriamente ditas. O cavalo, no âmbito do espaço cênico, estava associado a um complexo sistema de representações; de modo que, o efeito do "real" associado à presença física do animal, acabava por ser obliterado, em função dos muitos signos relacionados à ideia "cavalo". Se o ator laringotomizado falava de modo "visceral", o fazia como parte de uma artifício retórico que acabava por se tornar evidente pela maneira como o ator em cena assinalava para o público a palavra ars (arte). Ainda segundo Ridout, a tendência das críticas e relatos sobre o trabalho enfatizarem o "real" e não o "simulado" confere uma prova cabal não só da eficácia do fingimento, como também, de que o teatro ali se mantém em franca operação, jogando com o real para nos ludibriar, como num passe de mágica.

Cabe observar, de antemão, que, ao afirmar que a representação é algo, absolutamente, central no teatro, Ridout não faz outra coisa, senão retomar, de maneira menos direta, a questão da essência do teatro. Conforme nos lembra Patrice Pavis, a busca pela a especificidade do teatro, como meio de diferenciá-lo das demais artes - questão que, segundo o teórico francês, tanto obcecou a reflexão crítica - é sempre uma atitude meio metafísica, a partir do momento que se propõe a isolar uma certa substância que conteria todas as propriedades de todos os teatros. Para Pavis, toda concepção essencialista do teatro "nunca passa de uma ação estética e ideológica entre muitas outras. Ela faz abstração da relatividade histórica e cultural, demasiado preocupada com a descoberta de uma essência eterna e universalmente humana" (PAVIS, 2001, p.143)9.

Já, no que diz respeito à afirmação de que as produções da Societas Raffaello Sanzio nada mais são do que eficientes manifestações do "velho e bom teatro", caberia, antes de qualquer comentário, atentar para o fato de que o teatro performativo contemporâneo, ao qual a Societas Raffaello Sanzio se alia, ao evidenciar publicamente o corpo em seu estado de morte contínua, impede qualquer tipo de distinção segura entre arte e realidade, nos moldes do que parece sugerir Ridout. Ao subverter os princípios da ficção e da representação, esse tipo de teatro promove a sua própria "fenomenologia da percepção", alterando, de maneira radical, a lógica da percepção e o status do sujeito dessa percepção, o qual deixa de poder contar com o 
conforto de um ponto de fuga representacional/fabular qualquer, nos termos do que, comumente, ocorreria no caso do "velho e bom teatro" e sua separação nítida entre os universos do palco (plano da ficção) e da platéia (plano realidade).

A esse respeito, cabe lembrar, além do mais, o que considera Lyotard (1997) em seu texto "O dente, a palma", mais precisamente no trecho do ensaio em que o filósofo francês - rompendo, inclusive, com o termo "espectador", por estar intimamente ligado à predominância do aparato representacional na vida social - sugere a implosão da relação palco/ platéia e propõe, em seu lugar, uma relação do tipo palco + platéia, com a consequente abertura à exterioridade. De forma suplementar, Lehmann (2007), nas suas considerações sobre o teatro pós-dramático, constata que a obliteração das fronteiras entre arte e vida, alçando o espectador à condição de co-ator, faz com que o espaço teatral deixe de ser um espaço simbólico-metafórico e passe a ser concebido como um espaço contíguo ou metonímico; o que, por sua vez, podemos acrescentar, não impede que as cenas sejam operadas em espaços que encerram uma relação de frontalidade com a plateia, como costuma ocorrer nos trabalhos da SRSio.

\section{Dimensão anfibológica}

Se os argumentos de Ridout encerram proposições, de certa forma, problemáticas no tocante às discussões sobre a teatralidade contemporânea, por outro lado, eles não deixam de chamar a atenção para o que, de fato, existe no universo cênico da Societas Raffaello Sanzio em termos de uma antiteatralidade, drasticamente, teatral; ou, ainda, de uma teatralidade, radicalmente, anti-teatral - diferentemente do que costumava ocorrer, por exemplo, no caso das atividades de um performer como Kaprow, por exemplo, para quem "gerir um lugar de acontecimento entre as prescrições do ritual e o acaso da improvisação (ou a margem de liberdade oferecida pela execução múltipla (...) de uma mesma instrução ou de um mesmo guião), era ainda dar demasiada importância à teatralidade" (BADIOU, 2007, p.25)".

Obviamente, por mais infiltrada no cotidiano que seja, a performance sempre mobiliza uma focalização, um desvio "energético", uma dinâmica perceptiva, de modo que acaba envolvendo sempre uma certa teatralidade - como observou Kantor durante uma entrevista concedida numa fase tardia de sua trajetória artística, a arteésempreum tipo de exibicionismo. 
Contudo, nas atividades de Kaprow, esse "efeito de cena"12, esse dado teatral, parece surgir quase sempre a revelia e a contragosto dos agentes performáticos envolvidos na esteira de uma ação performativa que, como afirma Badiou, pretende eliminar mesmo a dimensão de encantamento poético da cena. Já nos instantes de exceção e desvio mobilizados pelos trabalhos da Societas Raffaelo Sanzio, pelo contrário, tem lugar uma espécie de "teatralidade sem teatro" que, operando por meio de "efeitos de realidade" e "transportação" sem ficção (se há traços de um "pré-texto" ficcional, eles parecem jamais se inscrever na superfície da cena), faz instaurar o "como se' do teatro, o destino de sua ficção, em uma dimensão ambivalente e anfibológica" (CASTELLUCCI, 2009, p.138); que poderia, eventualmente, ser relacionada àquilo que, conforme anteriormente dito, concerne à teatralidade manifestada pela via da identificação; ou ainda, pela via do espanto.

\section{NOTAS}

1. Ver LEHMANN, 2007, p.179-18o.

2. Interview Castellucci. Disponível em: <http://www.youtube.com/ watch? $\mathrm{v}=4 \mathrm{mfoMFLBAiQ}>$, acessado em janeiro de 2010 .

\section{DELEUZE, O Esgotado, versão não publicada, p.16}

4. Interview Castellucci. Disponível em: <http://www.youtube.com/ watch? $\mathrm{v}=4 \mathrm{mfoMFLBAiQ}>$, acessado em janeiro de 2010.

5. O próprio Castellucci afirma ter estudado muito pouco teatro. Sua formação é, basicamente, ligada ao campo das artes plásticas, além de ter estudado no Instituto Técnico Agrário e na Academia de Belas Artes de Bologna (curso de História da Arte).

6. Esse tipo de abordagem da cena por uma via liberta do timbre dos especialistas faz remissão, como nos lembra Cohen (2003), à proto-cena Dadá, ao Teatro da Crueldade de Artaud, às experiências limiares do happening, da performance e do teatro-performativo contemporâneo. No contexto da cena teatral brasileira, podemos reconhecer aspectos dessa abordagem nas montagens da Cia. Ueinzz, conduzida por Renato Cohen e Sérgio Penna, cujos integrantes eram usuários do Serviço de Saúde Mental do Hospital Dia "A Casa".

7. Obviamente, ao se promover o desfazimento de um organismo, devemos cuidar para que uma "overdose" no processo de desestratificação não nos faça cair num vazio inócuo. De acordo com Deleuze, não se conquista o que ele designa como plano de consistência a partir de uma supressão grosseira dos estratos. Diferentemente disso, devemos conservar sempre uma margem para a manifestação de pequenas provisões de organização, significância e interpretação, inclusive como maneira de contrapô-las a seu próprio sistema. Sem tal prudência, tangenciaríamos a morte, o falso, o ilusório. Só mesmo a partir de um jogo estreito com as estratificações podemos liberar as linhas de fuga, de modo a tornar possíveis a transação de fluxos conjugados e o agenciamento de intensidades contínuas para atingir o corpo sem órgãos.

8. Ver CORNAGO, 2010. 
9. A afirmação se torna, contudo, mais problemática quando se atenta para o que, de fato, ocupa, nos termos do que propõe Ridout, a centralidade do fenômeno teatral, a saber, a re-presentação.

10. Nestes casos, aliás, parece haver um desdobramento de um tipo de teatralidade relacionada a um tal efeito de percepção que surge por meio da convivência, a um só tempo, de uma "área de isolamento" e de um "espaço contíguo"; o que, por vezes, faz sugerir uma espécie de "transversão" do espaço "sagrado" (separado) em "profano", e vice-versa.

11. Traços dessa variante de "teatralidade antiteatral" - que se suspende ao mesmo tempo que se afirma, colocando-se à prova o tempo todo por meio de uma contínua confrontação consigo mesma - já se insinuavam na poética cênica de Gordon Craig. Deve-se ressaltar no entanto que, no contexto das produções da companhia italiana (SRZ), a pureza do dado "simbólico" craiguiano já não encontra mais espaço para a sua efetiva manifestação, passando a dar lugar à violência e à crueza do "real"; o que, como se sabe, vai totalmente de encontro às proposições idealistas do encenador inglês, para quem, cabe lembrar, "o Real ainda não é o teatral" (CRAIG, 2002, p. 78), ainda que, para Craig, esse real fosse preferível àquilo que seria o seu "outro extremo", a saber, o teatro de hypocrites em que seres humanos sobre um estrado, dando a impressão "vergonhosa" de serem atores, passam a personificar, representar ou interpretar um caráter. Sobre outros aspectos ligados à "tensão" entre as duas tendências antagônicas (uma de ordem teatral e outra de natureza anti-teatral) que, de forma concomitante, se afirmam nas projeções visionárias de Craig, ver BELLONI (2011).

12. Cabe lembrar aqui, de passagem, o que observa Luiz Costa Lima num trecho de seu estudo Mimesis: Desafio ao pensamento: "Se a ação da mímesis não se reduz ao natural e preliminarmente dado, é tanto mais porque envolve a correspondência entre a obra produzida e algo que provocado por ela, está fora de sua imanência: o seu efeito (wirkung)" (LIMA, 2000, p.354).

\section{Referências}

BADIOU, A.; DURING, E. Um Teatro da Operação: uma conversa entre Alain Badiou e Elie During. In: Um teatro sem teatro. Catálogo da exposição organizada pelo Museu d'Art Contemporani de Barcelona e co-produzida com o Museu Colecção Berardo - Arte Moderna e Contemporânea de Lisboa, 2007.

BELLONI, A. E. A. Teatro Menos Teatro. São Paulo: ECA/USP, 2011 (Tese de Doutoramento).

CASTELLUCCI, R. O peregrino da matéria. In: Sala Preta. São Paulo: ECA/USP, n.7, 2007, p. 181-187.

. A iconoclastia da cena e o retorno do corpo. A potência carnal do teatro. in: DIB, N. O Teatro experimental da Societas Raffaello Sanzio. ECA/USP, 2009 (Dissertação de Mestrado).

COHEN, R. Cartografia da cena contemporânea: matrizes teóricas e interculturalidade. In: Sala Preta. São Paulo: ECA/ USP, n.1, 2001. p. 105-112.

. Rito, Tecnologia e Novas Mediações na Cena Contemporânea Brasileira. In: Sala Preta. São Paulo: ECA/USP, n.3, 2003, p. 117-124. 
. et alii, Dicionário do Teatro Brasileiro - temas, formas e conceitos. São Paulo: SescSP/Perspectiva, 2006 (verbete multimídia).

CORNAGO, O. Teátrica pagã: diálogos de Jean-François Lyotard com a cena. In: Sala Preta. São Paulo: ECA/USP, n.1o, 2010. p. 371-381.

COWELL, C. Deleuze and Foucault: Series, Event, Genealogy. Theory E Event - Volume 1, Issue 2 The Johns Hopkins University Press, 1997.

CRAIG, E. Gordon. Scene. Londres: Oxford University Press, 1923. "Hamlet em Moscou: notas para uma breve alocução aos atores do teatro de Arte de Moscou". In: Sala Preta. São Paulo: ECA/USP, n.2, 2002. p. 78-81.

DELEUZE, Gilles. $O$ esgotado. Trad. Tomaz Tadeu. Não publicado.

One less manifesto. In: MURRAY, Thimothy. Mimesis, masochism $\mathcal{E}$ mime. The politics of theatricality in contemporary French thought. Ann Arbor, The University of Michigan Press, 2000, p. 239-258.

DELEUZE, Gilles e GUATTARI, Félix. Mil platôs. Capitalismo e esquizofrenia. Vol. 3. São Paulo: Editora 34, 1999.

DORT, Bernard. Le represéntation émancipée. Paris: Actes Sud, 1988. p. 171-184.

FÉRAL, Josette. "Performance and theatricality: the subject demystified". In: MURRAY, Thimothy. Mimesis, masochism \& mime. The politics of theatricality in contemporary French thought. Ann Arbor, The University of Michigan Press, 1997, p. 289-300.

. Por uma poética da performatividade: o teatro performativo. In: Sala Preta. São Paulo; ECA/USP. Volume 8, 2008. p.197-210.

. Theatricality the specificity of theatrical language. Substance 98/99, vol. 31, n. 2 e 3, 2002. p.94-108.

FERNANDES, Silvia. Teatralidades contemporâneas. In: Texto $e$ Imagem: estudos de teatro. Rio de Janeiro: Ed. 7 Letras, 2009.

KANTOR, Tadeusz. A arte é um tipo de exibicionismo. In: $\mathrm{Ca}$ dernos de Teatro, n.128, 1992.

KRAUSS, R. Caminhos da Escultura Moderna, São Paulo: Martins Fontes, 2007.

LEHMANN, Hans-Thies. Teatro Pós-dramático. São Paulo: Cosac Naify, 2007.

LIMA, L. Costa. Mimesis: Desafio ao pensamento. Rio de Janeiro: Civilização Brasileira, 2000. 
LYOTARD, Jean-François. O Inumano. Lisboa: Editorial Estampa, 1997.

. The tooth, the palm. In: MURRAY, Thimothy. Mimeses, masochism $\mathcal{E}$ mime, the politics of theatricality in contemporary French thought. Ann Arbor: The University of Michigan Press, 1997. p. 282-288.

PAVIS, Patrice. A encenação contemporânea. São Paulo: Ed. Perspectiva, 2010.

. Dicionário do Teatro. São Paulo: Perspectiva, 2001.

PUCHNER, Martin. Stage fright: Modernism, anti-theatricality $\mathcal{E}$ drama. Baltimore e Londres: The Johns Hopkins University Press, 2002.

RIDOUT, Nicholas. Make-believe: Societas Raffaello Sanzio do theatre. in. KELLEHER, Joe; Ridout, Nicholas (eds.). Contemporary theatres in Europe: a critical companion. London: Routledge, 2006. p. 175-187

TACKELS, Bruno. Societas Raffaello Sanzio, l'art de la pest. In: Les Castellucci. Besançon: Les Solitaires Intempestifs, 2005. p.25-45.

. Entretiens avec Romeo Castellucci. In: Les Castellucci. Besançon: Les Solitaires Intempestifs, 2005. p.80-91.

Recebido em: 25/o6/14

Aceito em: 11/o8/14

\section{ARTHUR E. A. BELLONI}

arbelloni@usp.br

Com experiência na área das artes (em Teatro Performativo), é mestre e doutor em Artes (área de concentração Artes Cênicas) pela Escola de Comunicações e Artes da Universidade de São Paulo (USP), e Bacharel em Artes Cênicas (habilitação em Direção Teatral) pela mesma instituição. É docente do Depto. de Artes Cênicas do Centro de Artes e Letras (CAL) da Universidade Federal de Santa Maria (UFSM) e integra o Grupo de Investigação do Desempenho Espetacular (GIDE).Atualmente, desenvolve projeto de pós-doutoramento no âmbito da Universidade do Minho (PT). 